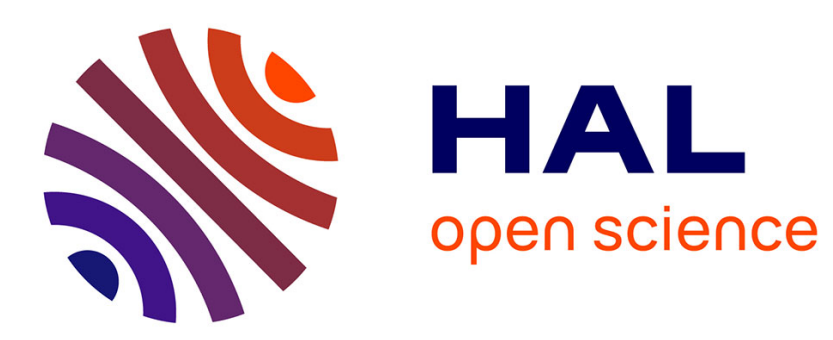

\title{
3D Microwave Imaging System for the Remote Detection and Reading of Passive Sensors
}

\author{
Dominique Henry, Patrick Pons, Hervé Aubert
}

\section{To cite this version:}

Dominique Henry, Patrick Pons, Hervé Aubert. 3D Microwave Imaging System for the Remote Detection and Reading of Passive Sensors. European Microwave Week (EuMW), Sep 2015, Paris, France. hal-01237578

\section{HAL Id: hal-01237578 \\ https://hal.science/hal-01237578}

Submitted on 3 Dec 2015

HAL is a multi-disciplinary open access archive for the deposit and dissemination of scientific research documents, whether they are published or not. The documents may come from teaching and research institutions in France or abroad, or from public or private research centers.
L'archive ouverte pluridisciplinaire HAL, est destinée au dépôt et à la diffusion de documents scientifiques de niveau recherche, publiés ou non, émanant des établissements d'enseignement et de recherche français ou étrangers, des laboratoires publics ou privés. 


\title{
3D Microwave Imaging System for the Remote Detection and Reading of Passive Sensors
}

\author{
D.Henry, P.Pons and H.Aubert \\ CNRS;LAAS;7 av. du colonel Roche \\ 31077 Toulouse, France \\ University of Toulouse; UPS, INSA, INP, ISAE; LAAS; \\ F-31077 Toulouse, France \\ dhenry@laas.fr,ppons@laas.fr, aubert@laas.fr
}

\begin{abstract}
This communication describes the use of a 3D microwave active imaging system based on a FrequencyModulated Continuous-Wave radar for the wireless localization, identification and reading of passive (battery-less) and chipless electromagnetic sensors. The beam scanning of the scene is performed mechanically and allows detecting passive sensors from the visualization of $3 D$ microwave image of a scene. A preliminary imaging system demonstrator operating at $24 \mathrm{GHz}$ is briefly described and resulting $3 D$ images are reported for different scenarios. An estimation of the maximal density of detectable passive sensors is given.
\end{abstract}

Keywords - 3D active imaging system; beam steering; FMCW radar; passive electromagnetic sensors

\section{INTRODUCTION}

In harsh environments with no easy access or when low-cost fabrication, long-term stability and small-size devices are a priority, passive (battery-less) and wireless electromagnetic (EM) sensors can be a suitable solution for the remote measurement of physical quantities such as pressure [1], temperature [2][3] or strain [4]. The passive EM sensors convert the variation of a physical quantity into a known/specific variation of a given EM wave descriptor. A Frequency-Modulated Continuous-Wave (FMCW) radar was recently used for the wireless measurement of a physical quantity from the analysis of the Radar Cross Section (RCS) variability of passive EM sensors [4]. Since 2010, this wireless and long-range (>30 meters) sensing technique based on RCSvariability measurement has been successfully applied to the remote estimation of many physical quantities (see an overview in [5]). However, up to now FMCW radar readers are used for the remote reading of passive sensors occupying known positions and consequently, the narrow beam of the radar transmitting antenna could be pointed in the direction of the sensor for maximizing the magnitude of the signal backscattered from the sensors. A slight deviation from the sensor direction of this beam may cause a significant reduction of the measured EM echo level.

To overcome these limitations and time-consuming adjustment of the beam direction we proposed here to perform a beam scanning and to detect passive sensors from the visualization of 3D microwave image of a scene. A number of FMCW radar and beam scanning systems were developed to obtain 3D image of different scenes but at least at the authors' knowledge, no application of such active imaging technique was devoted to the wireless localization, identification and remote reading of passive electromagnetic sensors. A preliminary imaging system demonstrator operating at $24 \mathrm{GHz}$ and using a mechanical beam steering is briefly described in this communication and the resulting $3 \mathrm{D}$ images are discussed for different scenarios. An estimation of the maximal density of detectable passive sensors is given.

\section{3D BEAM SCANNING FOR DETECTIING AND REMOTE READING PASSIVE SENSORS}

The interrogation of passive EM sensors is performed here by using a chirp generated by a Frequency Modulated Continuous Wave (FMCW) radar. The chirp has a linear sawtooth variation of frequency with time (modulation period of $T_{R}=18 \mathrm{~ms}$ ). The central frequency is $24 \mathrm{GHz}$ and the bandwidth or excursion frequency is $\Delta \mathrm{f}=2 \mathrm{GHz}$. Consequently the theoretical range resolution of the radar is $\mathrm{c} / 2 \Delta \mathrm{f}=7.5 \mathrm{~cm}$ (c denotes the vacuum celerity of light). The radar transmitting antenna is a Vivaldi horn antenna combined with a parabolic reflector to obtain a gain of $34.3 \mathrm{~dB}$ and narrow beamwidth ( $\Delta \theta=1$ degree in azimuth and $\Delta \varphi=1$ degree in elevation). Two $\mathrm{Rx}$-channels are used for receiving the signal backscattered from passive electromagnetic sensors. Each channel is an array of patch antennas with a beamwidth of 70 degrees in azimuth and 24 degrees in elevation. The received signal is mixed with the front-end transmitted signal and filtered for obtaining I- and Q-channels of the Difference Frequency Signal (DFS). These analog signals are finally digitalized. A Fast Fourier Transform of $\mathrm{N}_{\mathrm{FFT}}=1024$ samples is applied over the modulation ramp duration to obtain the beat frequency spectrum. A zero-padding with a pad factor $\mathrm{p}=2$ is applied to the spectrum. The maximal range $\mathrm{R}_{\mathrm{MAx}}$, which is limited by the bandwidth during the DFS calculation, is then given by [6]:

$$
\mathrm{R}_{\mathrm{Max}}=\frac{\mathrm{N}_{\mathrm{FFT}} \mathrm{C}}{4 \mathrm{p} \Delta \mathrm{f}}
$$

and the range quantization interval $\Delta \mathrm{R}$ is: 


$$
\Delta \mathrm{R}=\frac{\mathrm{c}}{2 \mathrm{p} \Delta \mathrm{f}}
$$

Consequently the FMCW radar used here provides a maximal range $R_{\text {Max }}$ of $19.2 \mathrm{~m}$ and a range quantization interval $\Delta \mathrm{R}$ of $3.75 \mathrm{~cm}$.

The 3D beam scanning of the scene is performed mechanically (see Fig. 1) with 1 degree step in azimuth $(\Delta \theta)$ and 0.25 degree step in elevation $(\Delta \varphi)$. The radar takes place into a corridor large enough to proceed to a sweep from -10 degrees to 10 degrees in azimuth and, -2degrees to 2 degrees in elevation. The movement of the Tx-antenna is synchronized with the radar controller and an average of 10 beat frequency spectra are recorded for each beam direction. Thus a 3D beam scanning of the scene involves here 57.120 resolution cells.

The electromagnetic and battery-less sensor is here passive scatterer composed of an horn antenna (gain: 20dBi; beamwidth: 60 degrees) connected to a length of TEM transmission line (a $50-\Omega$ coaxial cable of length $L=1.2 \mathrm{~m}$ ) which is in turn connected to a sensing device, that is, a resistance $\mathrm{R}_{\mathrm{L}}$ which depends on the physical quantity of interest (see Fig. 2). Four values of this resistance are considered in the experiment: (1) $\mathrm{R}_{\mathrm{L}}=50 \Omega$ (impedance matching condition), (2) $\mathrm{R}_{\mathrm{L}}=30 \Omega$, (3) $\mathrm{R}_{\mathrm{L}}=16.7 \Omega$ and (4) $R_{L}=0 \Omega$. The length $L$ of the transmission line is used here for separating in the beat frequency spectrum the structural scattering mode and the sensing mode (or antenna scattering mode). Only the EM echo corresponding to the sensing mode depends on the physical quantity of interest or equivalently on the sensing device resistance $\mathrm{R}_{\mathrm{L}}$. The structural scattering mode is used here for detecting and localizing the sensor. The antenna of the passive sensor is located at a distance $d=3.3 \mathrm{~m}$ from the FMCW radar. By taking into account the effective length of the transmission line (from radar to the Vivaldi horn) and the distance between the Vivaldi horn antenna and the parabolic reflector, the distance $\mathrm{D}$ between the sensor and the radar is found to be $4.5 \mathrm{~m}$.

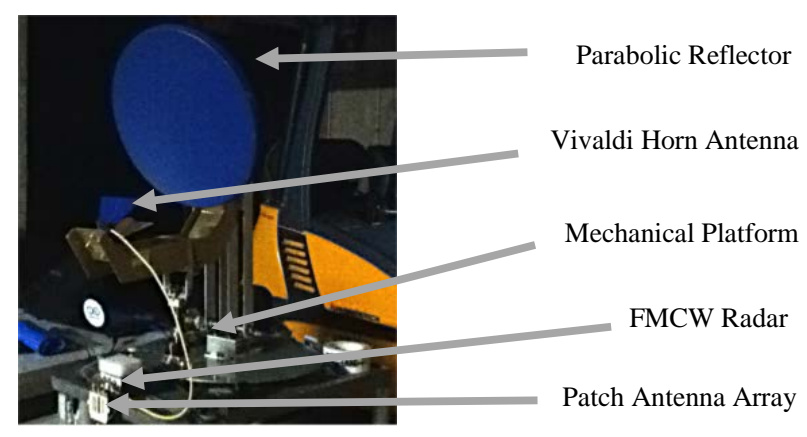

Fig. 1. 3D active imaging system with mechanical beam scanning

2D image in a cut plane at $\varphi=1^{\circ}$ are shown in Fig. 3 for $R_{L}=50 \Omega, R_{L}=30 \Omega, R_{L}=16.7 \Omega$ and $R_{L}=0 \Omega$. As expected, the structural scattering mode echoes due to the sensor horn antenna are visible at $4.5 \mathrm{~m}$ from the radar with an echo level higher than $-10 \mathrm{~dB}$. Moreover the sensing mode echoes due to the electromagnetic reflection on the resistance $R_{L}$ are found $1.2 \mathrm{~m}$ father. This distance corresponds to the effective length of the transmission line placed between the sensor antenna and the sensing device resistance $\mathrm{R}_{\mathrm{L}}$.

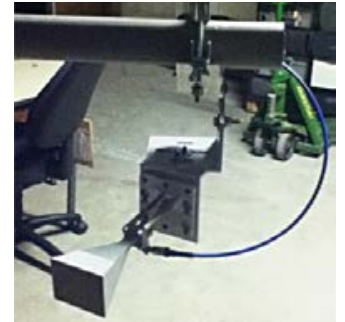

(a)

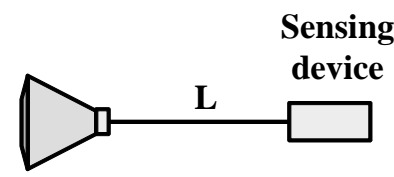

(b)
Fig. 2. (a) Photography and (b) illustration of the passive electromagnetic sensor used for visualizing and analyzing 3D microwave images

The echo level which corresponds to the sensing scattering modes is expected to decrease as the reflection coefficient $\Gamma$ on the resistance $R_{L}$ decreases. This behavior is enlightened in Fig.4 which displays the resolution cells for which the echo level is higher than a given threshold level. A threshold level of $-25 \mathrm{~dB}$ is chosen in order to clearly display the structural and sensing modes. The scene is here a volume defined by a depth $\mathrm{D}$ of $6 \mathrm{~m}$, by an elevation angle $\theta$ between -10 degree and 10 degrees and, by an azimuth angle $\varphi$ between -2 degrees and 2 degrees (57.120 resolution cells are required for displaying the 3D image of Fig. 4). It can be observed that, as the reflection coefficient $\Gamma$ decreases, the number $\mathrm{N}_{\mathrm{TH}}$ of cells in which the echo level is higher than the threshold level decreases. More specifically $\mathrm{N}_{\mathrm{TH}}=578$ when $\Gamma=1 \quad\left(\mathrm{R}_{\mathrm{L}}=0 \Omega\right)$ while $\mathrm{N}_{\mathrm{TH}}=352$ when $\Gamma=0\left(R_{L}=50 \Omega\right)$.

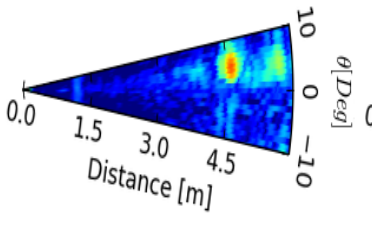

(a)

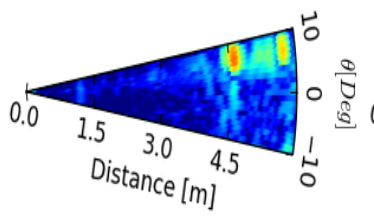

(c)

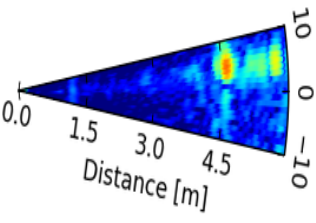

(b)

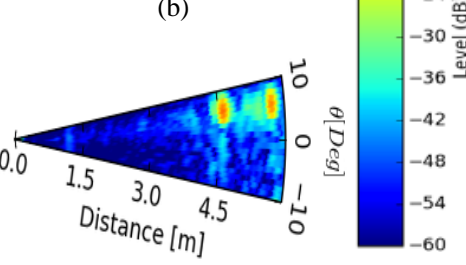

(d)
Fig. 3. 2D scanning in a cut-plane $\varphi=1^{\circ}$ for different impedance loading condition of the sensor: (a) $\mathrm{R}_{\mathrm{L}}=50 \Omega$ (impedance matching condition), (b) $\mathrm{R}_{\mathrm{L}}=30 \Omega$, (c) $\mathrm{R}_{\mathrm{L}}=16.7 \Omega$ and (d) $\mathrm{R}_{\mathrm{L}}=0 \Omega$.

Moreover, the highest density $\rho(d)$ of sensors that can be distributed at a given distance $\mathrm{d}$ from the radar can be estimated by:

$$
\rho(d)=\frac{1}{N_{S} V(d)}
$$


where $\mathrm{N}_{S}$ is the number of cells where the echo level is generated by a sensing mode at a given level threshold. $\mathrm{V}(\mathrm{d})$ is the volume of a resolution cell at distance $\mathrm{d}$ of the radar and is defined by :

$$
V(d)=\frac{1}{3}\left[\left(d+\frac{\Delta R}{2}\right)^{3}-\left(d-\frac{\Delta R}{2}\right)^{3}\right] \Delta \theta 2 \sin \left(\frac{\Delta \varphi}{2}\right)
$$

For higher densities than $\rho(d)$, echo level distribution of different passive sensors in a volume overlap and generate distinction issues. This analysis is valid for sensors that reflect the same echo level distribution. The density of sensors depends also of the chosen threshold level. A minimal threshold level increases the density but it has to be lower than the maximal echo level reflected. Table 1 shows $\rho(d=4.5 m)$ for $\mathrm{d}=4.5 \mathrm{~m}$ for different threshold levels. We consider a volume section of 4986 resolution cells containing only the sensing mode with $R_{L}=0 \Omega$ (with a maximal dynamic range). At this distance, a resolution cell has a volume $\mathrm{V}(\mathrm{d})=0.003 \mathrm{~m}^{3}$. The choice of this threshold is critical due to the fast variation of cells number $\mathrm{N}_{\mathrm{s}}$. If a too high threshold level is chosen, there is a risk to miss echo level data in future $R_{L}$ variations due to a lower dynamic range. Inversely, if the threshold level is too low, the density of sensors will not be optimal.

\begin{tabular}{|c|c|c|c|}
\hline Threshold level & $-25 \mathrm{~dB}$ & $-20 \mathrm{~dB}$ & $-15 \mathrm{~dB}$ \\
\hline $\mathrm{N}_{\mathrm{s}}$ & 273 & 137 & 26 \\
\hline$\rho(\boldsymbol{d}=\mathbf{4 . 5 m})$ & 1 sensors. $\mathrm{m}^{-3}$ & 2 sensors.m $\mathrm{m}^{-3}$ & 11 sensors. $^{-3}$ \\
\hline
\end{tabular}

Table 1. Highest density of sensors for different threshold levels in a sensing mode volume section where $R_{L}=0 \Omega$ at a distance $d=4.5 \mathrm{~m}$

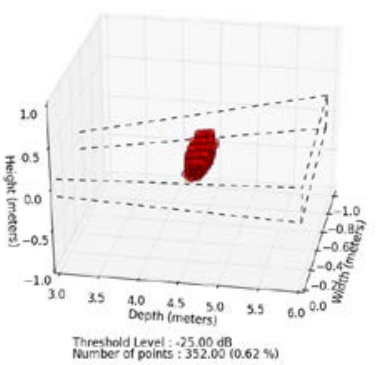

(a)

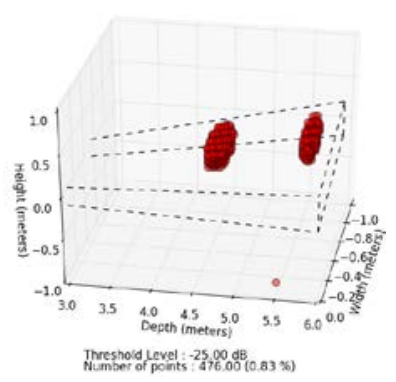

(c)

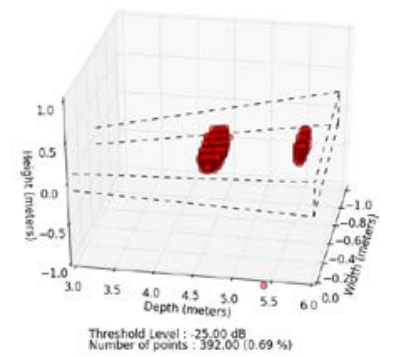

(b)

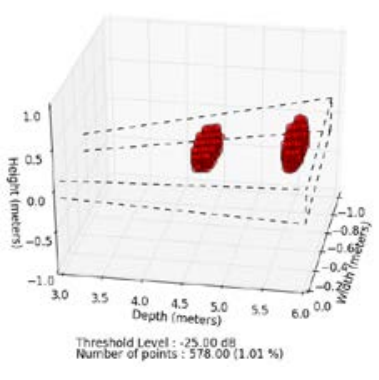

(d)
Fig. 4. 3D microwave images for different impedance loading condition of the sensor: (a) $\mathrm{R}_{\mathrm{L}}=50 \Omega$ (impedance matching condition), (b) $\mathrm{R}_{\mathrm{L}}=30 \Omega$, (c) $R_{L}=16.7 \Omega$ and (d) $R_{L}=0 \Omega$. The figure shows the resolution cells for which the echo level is higher than $-25 \mathrm{~dB}$.
The 3D imaging system can be advantageously used to wirelessly derive the variation of the resistance $R_{L}$ of the sensing device (in practice this variation originates in the fluctuation of the physical quantity of interest). In a given volume section, let $\mathrm{N}_{\text {Tot }}$ be the total number of resolution cells and let $\mathrm{N}_{\mathrm{n}}$ be the number of cells in which the echo level $\mathrm{P}$ is between $P_{n}$ and $P_{n+1}$. Fig. 5 sketches the typical variation of the echo level with the distance for a given beam direction (this variation is derived directly from the beat frequency spectrum measured by the FMCW radar reader) and indicates the resolution cells from which the number $\mathrm{N}_{\mathrm{n}}$ is calculated.

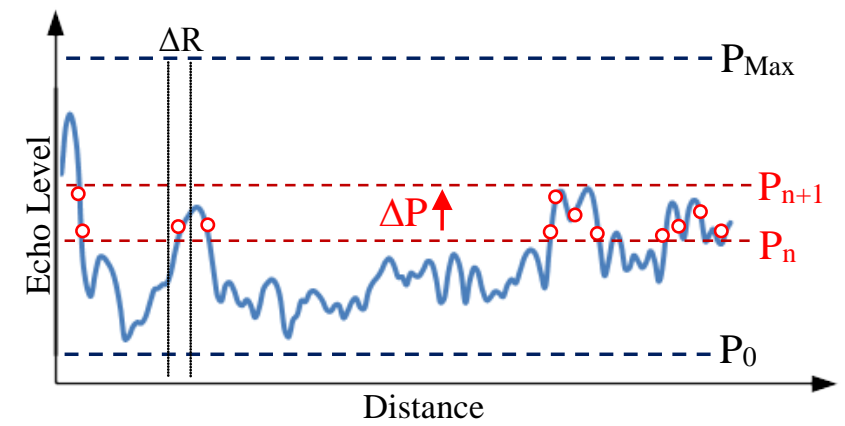

Fig.5. Typical beat frequency spectrum recorded from the FMCW radar for a given beam direction. The red circles indicate the resolution cells for which the echo level is between $P_{n}$ and $P_{n+1}$

We define the weight $\mathrm{W}_{\mathrm{n}}$ of the echo level $P$ by the following relationship:

$$
\mathrm{W}_{\mathrm{n}}=\frac{\mathrm{N}_{\mathrm{n}}}{\mathrm{N}_{\text {Tot }}}
$$

The weighted mean gives more importance to higher echo level values than the standard arithmetic mean and it allows a better dynamic measurement range for studying the echo level variation due to the fluctuation of the sensor resistance. If $\mathrm{W}_{0}$ denotes the weight of the noise echo level $\mathrm{P}_{0}$ and if $\mathrm{W}_{\mathrm{M}-1}$ designates the weight of highest echo level $\mathrm{P}_{\mathrm{Max}}$, it can be deduced that:

$$
\sum_{n=0}^{M-1} W_{n}=1
$$

and the weighted arithmetic mean $\mathrm{P}_{\mathrm{W}}$ of the echo level is then given by:

$$
\mathrm{P}_{\mathrm{W}}=\sum_{\mathrm{n}=0}^{\mathrm{M}-1} \mathrm{~W}_{\mathrm{n}} \mathrm{P}_{\mathrm{n}}
$$

Fig. 6 shows the weight distribution of the echo level for different scenarios in a volume section where sensing modes are included. The echo level step $\Delta \mathrm{P}=\mathrm{P}_{\mathrm{n}+1}-\mathrm{P}_{\mathrm{n}}$ is set to $0.5 \mathrm{~dB}$. The highest weight is reached when the echo level is about -45 $\mathrm{dB}$ and is slightly modified when the loading resistance varies even if the echo level is higher than $-40 \mathrm{~dB}$. Thus variations of the echo level offers a better dynamic range for an echo level $>$ -40dB. According to Eq.(7) the impact of the resistance variation on the weighted arithmetic mean can be measured by the quantity $\Delta \mathrm{P}_{\mathrm{W}}$ defined by: 


$$
\Delta \mathrm{P}_{\mathrm{W}}=\mathrm{P}_{\mathrm{W}}-\mathrm{P}_{\mathrm{Wref}}
$$

where $\mathrm{P}_{\mathrm{Wref}}$ denotes the weighted mean of the echo level when $\mathrm{R}_{\mathrm{L}}=50 \Omega$ and $\mathrm{P}_{\mathrm{W}}$ is the weighted mean of the echo level for $\mathrm{R}_{\mathrm{L}} \neq 50 \Omega$.

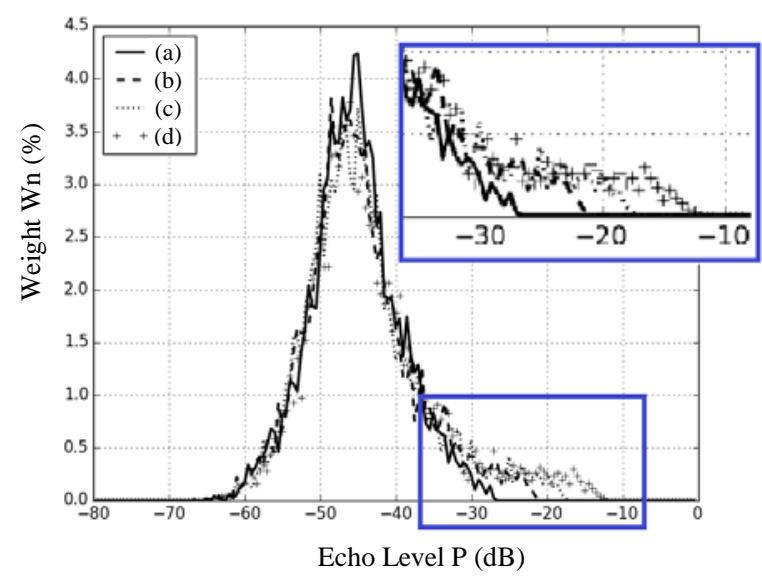

Fig. 6. Weight distribution vs the echo level for (a) $R_{L}=50 \Omega$ (impedance matching condition), (b) $R_{L}=30 \Omega$, (c) $R_{L}=16.7 \Omega$ and (d) $R_{L}=0 \Omega$.

Table 2 gives a summary of different mean values and the maximal echo level $\mathrm{P}_{\mathrm{Max}}$ for the four impedance loading conditions $\mathrm{R}_{\mathrm{L}}=50 \Omega, \mathrm{R}_{\mathrm{L}}=30 \Omega, \mathrm{R}_{\mathrm{L}}=16.7 \Omega$ and $\mathrm{R}_{\mathrm{L}}=0 \Omega$. $\mathrm{P}_{\text {Max }}$ gives important information about the maximal echo that can be reflected but can be only measured on a single direction in which the accuracy depends on the transmitting antenna main lobe width. $\mathrm{P}_{\mathrm{W}}$ offers a better dynamic range $(5.9 \mathrm{~dB})$ for load variation measurement from $0 \Omega$ to $50 \Omega$ than $\mathrm{P}_{\text {Average }}(2.1 \mathrm{~dB})$. This dynamic range is higher when the volume of calculation is shrunk to the sensing mode location but with loss of information for surrounding cells.

\begin{tabular}{|c|c|c|c|c|}
\hline & $\mathrm{R}_{\mathrm{L}}=50 \Omega$ & $\mathrm{R}_{\mathrm{L}}=30 \Omega$ & $\mathrm{R}_{\mathrm{L}}=16.7 \Omega$ & $\mathrm{R}_{\mathrm{L}}=0 \Omega$ \\
\hline$\Gamma$ & 0 & 0.25 & 0.5 & 1 \\
\hline $\mathbf{P}_{\text {Max }}$ & $-26.9 \mathrm{~dB}$ & $-21.2 \mathrm{~dB}$ & $-17.3 \mathrm{~dB}$ & $-12.2 \mathrm{~dB}$ \\
\hline $\mathbf{P}_{\text {Average }}$ & $-45.0 \mathrm{~dB}$ & $-44.4 \mathrm{~dB}$ & $-44.0 \mathrm{~dB}$ & $-42.9 \mathrm{~dB}$ \\
\hline $\mathbf{P}_{\mathbf{W}}$ & $-43.2 \mathrm{~dB}$ & $-41.2 \mathrm{~dB}$ & $-39.8 \mathrm{~dB}$ & $-37.3 \mathrm{~dB}$ \\
\hline$\Delta \mathrm{P}_{\mathrm{W}}$ & $\mathrm{NA}$ & $-55.2 \mathrm{~dB}$ & $-49.8 \mathrm{~dB}$ & $-43.4 \mathrm{~dB}$ \\
\hline
\end{tabular}

Table 2. Echo level measurement for different sensor resistance $\mathrm{R}_{\mathrm{L}}$

\section{CONCLUSION}

The 3D microwave images provided by the $24 \mathrm{GHz}$ FMCW radar scanning technology is a promising solution for wirelessly localizing and reading passive and chipless electromagnetic sensors. From a preliminary imaging system demonstrator 3D images have been obtained for different scenarios. An estimation of the maximal density of detectable passive sensors is given.

\section{REFERENCES}

[1] M. Jatlaoui, P. Pons, H. Aubert, "Radio-Frequency pressure transducer," European Microwave Conference, München, Germany, pp. 983-986, 2007

[2] T. Thai, M. Jatlaoui, H. Aubert, P. Pons, G. DeJean, M.Tentzeris, R. Plana, “A Novel Passive Wireless Ultrasensitive Temperature RF Transducer for Remote Sensing," IEEE International Microwave Symposium, Anaheim, California, USA, pp. 473-476, 23-28 May 2015

[3] T. Thai, M. Jatlaoui, F. Chebila, H. Aubert, P. Pons, G. DeJean, M. Tentzeris, R. Plana, "Design and Development of a Novel Passive Wireless Ultrasensitive RF Temperature Transducer for Remote Sensing,” IEEE Sensor Journal, Vol. 12, Issue 8, sept 2012, pp 2756-2766

[4] T. Thai, H. Aubert, P. Pons, G. DeJean, M.Tentzeris, R. Plana, "Novel Design of a Highly Sensitive RF Strain Transducer for Passive and Remote Sensing in Two Dimensions," IEEE Transactions on Microwaves Theory and Techniques, vol.61, Issue 3, pp. 1385-1396, March 2013

[4] H. Aubert, P. Pons, F. Chebila, M. Jatlaoui, Measurement Device Comprising an Electromagnetic Diffuser, Patent WO 2010/136388, May 29, 2009.

[5] H. Aubert, F. Chebila, M. Jatlaoui, T. Thai, H. Hallil, A. Traille, S. Bouaziz, A. Rifai, P. Pons, P. Menini, M. Tentzeris, "Wireless Sensing and Identification based on RADAR Cross Sections Variability Measurement of Passive Electromagnetic Sensors," Annals of Telecommunications, Special Issue on Chipless RFID, Vol. 68, Issue 7-8, pp. 425-435, August 2013

[6] Boris A. Atayans, Viacheslav M. Davydochkin, Victor V. Ezerskiy, Valery S. Parshin, Sergey M. Smolskiy, "Precision FMCW Short-Range Radar for Industrial Applications”, Artech House Publishers, April 2014 